\title{
The Influence of Sulfur Formation on Performance and Reforming Chem- istry of SOFC Anodes Operating on Methane Containing Fuel
}

\author{
Matthias Riegraf, ${ }^{\mathrm{a}, \mathrm{z}}$ Vitaliy Yurkiv, ${ }^{\mathrm{a}}$ Günter Schiller, ${ }^{\mathrm{a}}$ Rémi Costa, ${ }^{\mathrm{a}}$ Arnulf Latz, ${ }^{\mathrm{a}, \mathrm{b}} \mathrm{K}$. Andreas \\ Friedrich $^{\mathrm{a}}$
}

${ }^{a}$ German Aerospace Center (DLR), Institute of Engineering Thermodynamics, Pfaffenwaldring 38-40, 70569

$$
\text { Stuttgart, Germany }
$$

${ }^{\mathrm{b}}$ Helmholtz Institute Ulm (HIU), Electrochemical Energy Storage, Albert-Einstein-Allee 11, 89081 Ulm, Germany

${ }^{\mathrm{z} C}$ Corresponding author: E-mail: Matthias.Riegraf@dlr.de, Phone: +49 (0) 711 6862-8027, Fax: +49 (0) 711

$6862-747$

E-mail address: Guenter.Schiller@dlr.de (Günter Schiller), Remi.Costa@dlr.de (Rémi Costa), Andreas.Friedrich@dlr.de (K. Andreas Friedrich), Arnulf.Latz@dlr.de (Arnulf Latz), Vitaliy.Yurkiv@dlr.de (Vitaliy Yurkiv)

Keywords: Solid oxide fuel cell (SOFC), Ni/YSZ anode, sulfur poisoning, degradation, elementary kinetic modeling, methane reforming

\section{Highlights:}

We performed elementary kinetic simulations of Ni/YSZ SOFC anodes operating on methane containing fuels considering sulfur formation

Performance and degradation under sulfur exposure were analyzed at both OCV and current load

Adsorbed sulfur strongly impacts methane reforming suppressing hydrogen and carbon monoxide production 


\begin{abstract}
This paper presents a detailed analysis of the influence of sulfur formation on performance and efficiency of Solid Oxide Fuel Cells (SOFC) operating on methane containing fuels. Our previously developed multi-step reaction mechanism of sulfur formation and oxidation is coupled with a complex heterogeneous mechanism of methane reforming, channel gas-flow, porous-media transport and elementary kinetic charge transfer and is used to describe sulfurinduced degradation and performance drops of Ni/YSZ anodes. Experimental literature data is used to validate the model and to interpret important aspects of cell performance degradation. Comparisons of the model predictions to the experiments illustrate that the developed model, without any modifications, reproduces the observed voltage decrease well and is able to capture the changes in fuel conversion and selectivity for different gas mixtures. It is shown that atomically adsorbed sulfur significantly influences heterogeneous reforming chemistry, causing substantial voltage degradation. At constant current densities, cell voltage decreases in a non-linear way with faster recovery than in $\mathrm{H}_{2} / \mathrm{H}_{2} \mathrm{O}$ mixture.
\end{abstract}




\section{Introduction}

The enormous usage of fossil fuels over the last decades has led to a large release of green-house gases negatively impacting the climate change. Thus, there is an increased need to develop alternative energy conversion technologies with a reduced carbon-footprint. In this regard, the Solid Oxide Fuel Cell (SOFC) is a promising alternative technology for future energy supply. Due to a high operating temperature range (800 K - $1100 \mathrm{~K})$, SOFCs are capable of utilizing a variety of fuels, such as natural gas, biomass gasification products, or syngas. ${ }^{1-3}$ However, most of these fuels contain compounds undesired for SOFC operation. One of such substances is hydrogen sulfide $\left(\mathrm{H}_{2} \mathrm{~S}\right)$, which causes drastic decrease of cell performance in a short period of time, particularly when a Ni/YSZ cermet is employed as anode material. Therefore, the major objective of this paper is to explore and interpret the influence of sulfur formation at the nickel surface of SOFC anodes on performance and in particular on methane reforming chemistry.

Numerous studies have experimentally investigated the influence of sulfur poisoning on $\mathrm{Ni} / \mathrm{YSZ}$ anodes operated on $\mathrm{H}_{2} / \mathrm{H}_{2} \mathrm{O}$ fuel gas mixtures identifying the electrochemical hydrogen oxidation process to be severely hindered under these conditions. ${ }^{4-10}$ However, in recent years, a growing number of studies have been dedicated to the investigation of sulfur poisoning of Ni/YSZ SOFC anodes operating on hydrocarbon-containing fuels, such as methane, ${ }^{11-}$ ${ }^{13}$ reformates, ${ }^{14}$ syn- ${ }^{15,16}$ and biogas. ${ }^{1}$

Regardless of the employed fuel gas mixture, in all experimental studies a rapid power output drop was observed already for $\mathrm{H}_{2} \mathrm{~S}$ concentrations in the ppm range accompanied by a large increase in total anode resistance. ${ }^{11,13-15,17}$ This drop is generally believed to be the result of the chemisorption of sulfur on the active surface sites resulting in a blockage of the electrochemical oxidation and internal catalytic reforming reactions. The removal of $\mathrm{H}_{2} \mathrm{~S}$ from the gas feed usually leads to a complete recovery after short-time exposure. ${ }^{13,18}$ 
It has been shown in several experimental studies that the reforming activity is poisoned to a larger extent than the electrochemical reactions strongly affecting the cell voltage already at open circuit voltage $(\mathrm{OCV}) .^{11,13,16,18-21}$ The increased sensitivity of steam reforming towards sulfur poisoning has been attributed to the preferred sulfur adsorption on step sites which are particularly active for methane reforming. ${ }^{20}$ Generally, higher $\mathrm{H}_{2} \mathrm{~S}$ concentrations lead to larger cell performance drops. However, constant cell performance is reached once sulfur approaches its saturation coverage on $\mathrm{Ni}^{13,18}$ For example, an elimination of $60 \%$ of the initial reforming activity already at $4 \mathrm{ppm} \mathrm{H}_{2} \mathrm{~S}$ content under OCV conditions was observed in a comprehensive study by Rasmussen et al. ${ }^{13}$ Subsequently, the reforming activity was found to stay nearly constant for $\mathrm{H}_{2} \mathrm{~S}$ concentrations of $20 \mathrm{ppm}$ and higher. ${ }^{13}$ They observed that under current density a maximum $\mathrm{H}_{2} \mathrm{~S}$ concentration of only $7-9$ ppm was possible before the cell voltage broke down which led to cell failure. In a different study, it was demonstrated that sulfur poisoning has a major influence on both mass and charge transfer via impedance spectroscopy measurements. ${ }^{18}$ It was shown that upon $\mathrm{H}_{2} \mathrm{~S}$ exposure at low current densities, the increase of charge transfer/TPB polarization resistance dominates, whereas at higher current densities the increase of resistance due to mass transfer and fuel reforming processes is the main deactivation effect. Moreover, the possibility of fuel starvation already at low current densities due to the combined effect of deactivated reforming reactions and high fuel consumption was indicated. ${ }^{13,18}$

Several experimental studies have examined the sulfur poisoning of $\mathrm{CO} / \mathrm{H}_{2} / \mathrm{H}_{2} \mathrm{O}$ gas mixtures in order to extract detailed information about the influence of sulfur on the water gas shift reaction, as a first step towards the elucidation of the poisoning of the methane steam reforming process. ${ }^{14,16,22,23}$ The results of these studies show that the water gas shift reaction is also affected more strongly than the electrochemical oxidation of hydrogen, which entails a lack of hydrogen for gas phase mixtures with high CO contents. 
The magnitude of the performance drop has been found to be alleviated by increasing temperatures generally believed to be due to reduced surface sulfur coverage. ${ }^{5,7,18,24}$ However, controversial interpretations of experimental studies exist regarding the influence of current density on the sulfur poisoning of Ni-based anodes. First, the unusual effect of poisoning processes with current density was observed for simple $\mathrm{H}_{2} / \mathrm{H}_{2} \mathrm{O}$ gaseous mixtures. Several authors have reported a lower relative increase of total anode resistance for increasing current densities. ${ }^{5,6,25}$ In these studies, the sulfur surface coverage was suggested to decrease with higher current density as to its electrochemical oxidation and subsequent desorption as $\mathrm{SO}_{2}$. Recently, Cheng et al. have noted that in the Tafel region the relative increase of the total anode resistance due to sulfur poisoning inherently depends inversely on current density. ${ }^{26}$ Thus, reduced sulfur surface coverage might not necessarily be the reason for the observed trend. Other studies, involving methane containing fuels, have indeed observed a different behavior. Upon poisoning of $\mathrm{Ni} / \mathrm{ScSz}$ anodes, Yoshizumi et al. found a greater increase of anode overvoltage with increasing current density for operation with pre-reformed methane. ${ }^{12}$ Moreover, Hagen et al. have indicated that increasing current density does not alleviate sulfur poisoning of electrochemical reactions during internal methane steam reforming. ${ }^{18}$

Based upon the reviewed works above, it is evident that sulfur formation in the anode of SOFC, detrimentally influences the rate of reforming reactions, which is directly reflected in performance characteristics of the fuel cell. Thus, sulfur poisoning of SOFC fuelled with hydrocarbons is a complex phenomenon due to the interplay of many factors, such as heterogeneous catalytic reactions, charge-transfer, channel and porous media flow, and deactivation of active surface area and TPB.

To allow for a deeper understanding of the processes leading to sulfur poisoning, this study presents a modeling work of anode-supported SOFC operating on $\mathrm{CH}_{4} / \mathrm{H}_{2} / \mathrm{H}_{2} \mathrm{O}$ gas mixtures with different hydrogen sulfide $\left(\mathrm{H}_{2} \mathrm{~S}\right)$ concentrations. Among many SOFC modeling works the thermal catalytic surface chemistry is neglected or represented as empirical global 
chemistry, which precludes the establishment of the influence of sulfur formation. In this work we employ an elementary kinetic description of methane reforming chemistry and electrochemistry to account for the influence of sulfur formation on SOFC performance. In order to interpret experimental measurements, the previously developed kinetic model ${ }^{24}$ is used comprising a detailed multi-step reaction mechanism of sulfur formation and oxidation at $\mathrm{Ni} / \mathrm{YSZ}$ anodes.

\section{Approach and modeling summary}

Our previously developed elementary reaction mechanism ${ }^{24}$ is applied to analyze experiments of Rasmussen et al., ${ }^{13}$ which were conducted using Ni/YSZ based anode supported SOFC. These experiments stand for the most complete data set available at present and cover an extended range of operating conditions. The membrane-electrode assembly (MEA) used by Rasmussen et al. consists of five distinct layers: $(i)$ a fuel chamber ( $4 \mathrm{~cm}$ width) in horizontal direction, where fuel $\left(\mathrm{CH}_{4}, \mathrm{H}_{2}, \mathrm{H}_{2} \mathrm{O}\right)$ is introduced to the cell and products are carried out of it, (ii) a porous Ni/YSZ anode $(315 \mu \mathrm{m}),($ iii) a dense YSZ electrolyte membrane $(15 \mu \mathrm{m})$, where oxygen anions migrate from cathode to anode, (iv) an LSM/YSZ porous cathode (25 $\mu \mathrm{m})$, where oxygen gas is reduced to oxygen anions, and ( $v)$ a cathode supply channel, where air enters the cathode side delivering oxygen. The detailed description of the used SOFC configuration is given in Ref. ${ }^{13}$ and briefly summarized in Table I.

Modeling summary. - The employed physical model is based upon our previously published approach ${ }^{27}$ and has been successfully applied in different energy-related fields, ${ }^{28,29}$ thus, only a brief summary is given here. Fig. 1 illustrates the experimental cell configuration used in our model together with some of the physico-chemical processes in a schematic representation. 
Fuel and air enter the cell through the channels parallel to the electrode surface and their flow is modeled based upon a plug-flow approximation using a 1D representation of the Navier-Stokes equation. At the anode side, when fuel reaches the catalyst, methane reforming proceeds via catalytic chemistry within the anode support structure. The reforming chemistry within the Ni-YSZ anode is coupled to sulfur formation/oxidation reactions and is modeled using an elementary kinetic reaction approach. The porous-phase transport within the electrode is modeled using Stefan-Maxwell diffusion and Darcy viscous flow. Gas-phase chemistry is neglected owing to very small reaction rates for methane reforming at temperatures below $1150 \mathrm{~K}^{30}$ The transport of ions through the electrolyte is included as charge conservation equation assuming a temperature-dependent ionic conductivity with constant ion and vacancy concentrations.

Many of the parameters are physical quantities that can be established. However, as with most models, other parameters are empirical. For example, anode specific surface area, TPB length, etc., are not measured independently. They are rather adjusted to provide a good representation of measured polarization characteristics over a certain range of operating conditions. It is possible to estimate effective parameters such as the porous-media tortuosity and porosity using detailed microstructural modeling. ${ }^{31}$ However, we follow the approach of adjusting these parameters to assist with representing concentration polarization at high current density.

Since the elemental sulfur formed on the surface reduces the active Ni area we assume its dependency on sulfur coverage as follows

$$
A_{\mathrm{Ni}}^{\mathrm{V}}=A_{\mathrm{Ni}, 0}^{\mathrm{V}} \cdot e^{-a \cdot \theta\left(\mathrm{S}_{\mathrm{Ni}}\right)},
$$

where $A_{\mathrm{Ni}}^{\mathrm{V}}$ describes the volume-specific surface area, $A_{\mathrm{Ni}, 0}^{\mathrm{V}}$ denotes the initial volume-specific surface area and $\theta\left(\mathrm{S}_{\mathrm{Ni}}\right)$ is the sulfur coverage on the Ni surface. 
Since the adsorption of atomic sulfur on the Ni surface occurs on hexagonal closed packed (hcp) and face centered cubic (fcc) sites $^{32}$ with strong lateral repulsion, it reflects in significant active surface blockage. Experimental investigations of the sulfur surface structure on $\mathrm{Ni}$ catalysts have shown that the surface structure continuously changes with coverage and that especially for high sulfur surface coverages numerous complex surface patterns can be formed that are only stable in a small coverage range. ${ }^{33,34}$ However, modeling this highly nonlinear relationship between sulfur coverage and blocked surface area at such a high level of resolution would be virtually impossible. In our study we have employed an inversely exponential approach which has proven to capture this effect well for the whole investigated sulfur coverage range. In order to account for the atomic level interaction between adsorbed sulfur and active surface area a steric coefficient $a$ is used in equation 1 , which is set to the constant value nine for all simulations.

Simulation methodology.- Simulations were carried out using the in-house software package DENIS. All model equations used in the present modeling and simulation work are thoroughly described in Refs. ${ }^{27,35}$ Spatial derivatives are discretized using the finite-volume method and the resulting differential-algebraic equation (DAE) system is integrated using the semi-implicit extrapolation solver LIMEX ${ }^{36}$ In the present work, transient and steady-state problems were solved both of which emerging during SOFC characterization. Electrochemical impedance spectra are simulated using a potential step and current relaxation technique. ${ }^{37}$ The impedance is obtained in the frequency domain by a Fourier transformation of the resulting time-domain traces of current and potential. For transient simulations (voltage stability) at each time step the solution (current density) is determined by solving the transient system, and in the case of steady-state simulations (polarization curves), calculations are carried out by solving the transient system until a steady-state is reached, then the respective current density is evaluated at a given overpotential. 
Heterogeneous and charge-transfer chemistry. - As discussed above, the inlet gas mixture at the anode side consists of $\mathrm{CH}_{4}, \mathrm{H}_{2}, \mathrm{H}_{2} \mathrm{O}$ and $\mathrm{H}_{2} \mathrm{~S}$ gases, and after reforming on the $\mathrm{Ni}$ catalyst furthermore contains the four additional gas phase species $\mathrm{CO}, \mathrm{CO}_{2}, \mathrm{O}_{2}$ and $\mathrm{SO}_{2}$. In order to describe this complicated heterogeneous mechanism, we have combined two validated reaction mechanisms: first, the full methane reforming mechanism on the nickel surface consisting of 42 surface reactions among 6 gas phase species and 14 surface-adsorbed species, ${ }^{38,39}$ and second, the recently developed elementary kinetic mechanism of sulfur formation/oxidation on the nickel surface including charge-transfer between $\mathrm{Ni}$ and YSZ and heterogeneous chemistry on YSZ. ${ }^{24}$ LSM/YSZ cathode electrochemistry is modeled using a global Butler-Volmer approach according to Zhu et al. ${ }^{40}$ Since all relevant thermodynamic and kinetic data are thoroughly described in the references given above, it is not repeated here. However, a schematic illustration of the coupled mechanisms of methane reforming and sulfur poisoning is shown in Fig. 2. In this figure the methane reforming steps are shown on the right in black, whereas $\mathrm{H}_{2} \mathrm{~S}$ dissociation and $\mathrm{SO}_{2}$ formation, which leads to the degradation of the cell, is shown in bold and blue on the left of the schema.

In order to obtain a physically meaningful description of SOFC anode poisoning by the formation of surface sulfur, a thermodynamic and kinetic data set for the respective reaction species and elementary reactions was derived. ${ }^{24}$ It consists of hydrogen sulfide adsorption and dissociation on Ni surface with consecutive sulfur oxidation. All thermodynamic and kinetic data was derived based on literature available first-principles density functional theory (DFT) calculations and chemical reactor experiments. Regarding the thermodynamic data of nickel-adsorbed sulfur, a coverage-dependent enthalpy was assumed, which was derived based on $\mathrm{H}_{2} \mathrm{~S}$ adsorption isotherms for a variety of conditions.

The employed methane reforming mechanism was developed to describe steam reforming (SR), partial oxidation (POX) and dry reforming (DR) of methane on the Ni surface. From an elementary kinetic point of view, all of these chemical processes are based on identi- 
cal elementary steps. ${ }^{41,42}$ Therefore, it is evident that SR, POX and DR cannot be seen as three independent reaction pathways, and they are inherently coupled forming a complex heterogeneous chemical reaction mechanism. The dominating process among these three global reactions is determined by a number of factors, all of which are interdependent: (a) the gas-phase composition and, therefore, the availability and ratio of surface species, (b) the reaction kinetics and mobility of the surface species, which depend on temperature and the materials system, (c) the location of the adsorption reactions relative to the three-phase boundary (adjacent or distant to the three-phase boundary), (d) the location within the porous anode (close to the supply channel or to the electrolyte). For that reason, one of the aims of the present work is to establish the influence of sulfur formation on the heterogeneous chemistry. Complex simulations of experimental electrochemical measurements are performed to analyze this influence, taking into account an elementary kinetic surface mechanism coupled to electrochemistry, additional degradation processes and transport phenomena at different scales.

Charge-transfer chemistry is also modeled using an elementary kinetic approach as described in our previous work. ${ }^{24,43}$ The charge-transfer reaction occurs via hydrogen spillover that transfers a proton from $\mathrm{Ni}$ to a hydroxyl ion on YSZ forming water and delivering one electron to the Ni.

\section{Results and Discussion}

In order to verify our developed model and its base parameter set, we have validated it against electrochemical measurements of Rasmussen et al. ${ }^{13}$ using the system without sulfurcontaining gases. Firstly, we simulated the I-V curve of an anode-supported cell and, subsequently, voltage stability tests at different conditions were reproduced. Figure 3 illustrates the predicted polarization features of the nominal MEA structure (see Table I) operating on $\mathrm{CH}_{4}$, $\mathrm{H}_{2}$ and $\mathrm{H}_{2} \mathrm{O}$ at $1123 \mathrm{~K}$ and $1 \mathrm{~atm}$. In the original paper there was no complete experimental polarization curve available, however, based upon comparisons to the given I-V data points 
by Rasmussen et al., as described further below, our predicted polarization characteristics describe the experimental cell well. The simulated open circuit voltage (OCV) of $995 \mathrm{mV}$ is in good agreement with the measured value of $984 \mathrm{mV}$. Also, a fuel utilization (FU) of $57 \%$ for a current density of $1 \mathrm{~A} \cdot \mathrm{cm}^{-2}$ was reported for the experiments which is in accordance with our simulated value as depicted in Fig. 3. The peak power density of $0.8 \mathrm{~W} \cdot \mathrm{cm}^{-2}$ is reached for a current density of $1.5 \mathrm{~A} \cdot \mathrm{cm}^{-2}$ and a voltage of $0.55 \mathrm{~V}$. At high current density the strong influence of transport limitations is apparent as the FU is approaching $100 \%$. The significant polarization due to gas transport is in good agreement with the experimentally observed $40 \%$.

In the following, two cases will be discussed. First, the comparison of our model predictions with the electrochemical results under OCV (no voltage applied), and second, the comparison between simulated and experimental results for certain applied biases.

Cell operation at open circuit. - This section shows the comparison between our simulations and sulfur poisoning experiments by Rasmussen et al. ${ }^{13}$ for a temperature of $1123 \mathrm{~K}$ at OCV. First, the OCV stability tests over 270 hours are reproduced in which the model is run with time-varying inputs monitoring different electrochemical performance changes. Figure 4 shows the results of the transient simulations for a $29 \% \mathrm{CH}_{4}, 13 \% \mathrm{H}_{2}, 58 \% \mathrm{H}_{2} \mathrm{O}$ gas mixture containing $2,4,7,9,20$ and $24 \mathrm{ppm}$ of $\mathrm{H}_{2} \mathrm{~S}$. At the beginning, up to 6 hours, the OCV has a constant value of $0.995 \mathrm{~V}$, as long as no $\mathrm{H}_{2} \mathrm{~S}$ has been introduced to the system. However, starting from 7 hours the OCV gradually decreases over 43 hours upon operation with a constant $\mathrm{H}_{2} \mathrm{~S}$ concentration of $2 \mathrm{ppm}$. After about 30-40 h of $\mathrm{H}_{2} \mathrm{~S}$ exposure the cell voltage reaches a constant value. In the following, the increase of $\mathrm{H}_{2} \mathrm{~S}$ concentration initially leads to a further decrease of voltage, however, for $\mathrm{H}_{2} \mathrm{~S}$ concentrations higher than $20 \mathrm{ppm}$ the cell voltage stabilizes. Moreover, the initial decrease of cell voltage for $2 \mathrm{ppm} \mathrm{H}_{2} \mathrm{~S}$ proceeds at a much lower rate than the subsequent drops with increasing $\mathrm{H}_{2} \mathrm{~S}$ concentrations. A removal of 
$\mathrm{H}_{2} \mathrm{~S}$ from the feed gas results in a nearly complete voltage recovery in the experiments. The slight overestimation of the simulated OCV after the recovery is probably due to a certain extent of irreversible degradation which was not accounted for in our simulations. Nevertheless, Fig. 4 shows a very good overall agreement between experiments and simulations over the whole investigated time period.

In the original paper, Rasmussen et al. have indicated hindered methane steam reforming and the associated change of the gas phase composition to be the reasons for the cell voltage decrease and its stabilization to be due to the saturation of sulfur surface coverage. In order to allow for an in-depth analysis of this explanation, we have simulated the evolution of the mean coverage of selected Ni surface species over 270 hours corresponding to the OCV stability test from Fig. 4. The results depicted in Figure 5 show that the initial addition of 2 ppm $\mathrm{H}_{2} \mathrm{~S}$ leads to a significant increase in sulfur coverage and a simultaneous reduction of hydrogen and $\mathrm{CO}$ coverage. Subsequently, with a further increase in $\mathrm{H}_{2} \mathrm{~S}$ concentration sulfur surface coverage approaches its saturation value of $0.5 \mathrm{ML}^{44}$ and the hydrogen and CO coverage stabilize. It can be seen that after the introduction of $2 \mathrm{ppm}_{2} \mathrm{~S}$ the cell voltage reduction and the increase of sulfur coverage happen simultaneously. The comparatively slow rate of this initial poisoning process is likely to be due to the only gradual replacement of the original surface adsorbates with corresponding slow desorption rates. This takes a particularly long time, as the initial poisoning entails by far the largest increase in sulfur coverage.

In order to further interpret the actual influence of sulfur formation on heterogeneous reforming chemistry and cell performance, the predicted gas phase species distributions in the channel and within the anode structure for the time points of $6 \mathrm{~h}, 50 \mathrm{~h}$ and $220 \mathrm{~h}$ (corresponding to $\mathrm{H}_{2} \mathrm{~S}$ exposure of 0, 2 and 24 ppm) are illustrated in Fig. 6a,b,c. Along the length of the channel, methane is catalytically reformed to produce $\mathrm{CO}$ and $\mathrm{H}_{2}$ in all three cases. Gaseous $\mathrm{H}_{2} \mathrm{O}$ is the most abundant gas phase species at the channel inlet and takes part in two important catalytic processes on the Ni surface. One of them is the $\mathrm{CH}_{4}$ steam reforming reac- 
tion and the second is the water-gas shift reaction (WGS), where $\mathrm{CO}$ and $\mathrm{H}_{2} \mathrm{O}$ are converted into $\mathrm{H}_{2}$ and $\mathrm{CO}_{2}$. Carbon dioxide, which is mainly a reaction product of WGS, additionally participates in the dry reforming of $\mathrm{CH}_{4}$ to form $\mathrm{CO}$ and $\mathrm{H}_{2}$.

For the non-sulfur system depicted in Fig. 6a, full methane conversion (steam reforming) is reached quickly leading to equilibrated gas-phase profiles along the channel after already about one third of its length. The analysis of the gas-phase profiles in the channel shows that the dry reforming reaction rate is smaller than that of WGS, as there is a certain formation of $\mathrm{CO}_{2}$ which was absent in the initial fuel gas mixture. However, the equilibrium partial pressure of $\mathrm{CO}_{2}$ is comparatively low due to the high hydrogen gas phase concentration promoting the reverse water gas shift reaction (r-WGS).

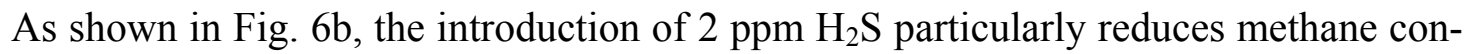
version at the fuel inlet. At a channel length of approximately $0.75 \mathrm{~cm}$, the methane conversion rate starts to increase strongly and the gas phase composition approaches the equilibrium composition as shown at the outlet of Fig. 6a.

It is known from catalysis that sulfur coverage on Ni can be described by the Temkin isotherm and was shown to be a function of hydrogen partial pressure. ${ }^{37}$ Thus, the severe hindrance of methane conversion at the inlet of the channel can be explained with a comparatively high sulfur surface coverage on $\mathrm{Ni}$ at the channel inlet and the corresponding blockage of the active surface area. The initial formation of $\mathrm{H}_{2}$ gas from methane conversion is very slow, but initiates a domino effect where the sulfur coverage decreases with increasing $\mathrm{H}_{2}$ partial pressure inducing an acceleration of methane conversion.

Even though methane is nearly fully converted at the fuel outlet, the low $\mathrm{H}_{2}$ concentration at the fuel inlet entails a smaller local electromotive force compared to Fig. 6a leading to the measured cell voltage drop.

With a further increase of $\mathrm{H}_{2} \mathrm{~S}$ concentration to $24 \mathrm{ppm}$, the poisoning behavior becomes even more severe. The gas phase profile at the beginning resembles the imposed inlet 
gas phase concentration and only changes slowly along the channel. There is only a small formation of $\mathrm{CO}$ and $\mathrm{CO}_{2}$ gases towards the end of the channel demonstrating strongly reduced reforming activity. The initiation of the domino effect described for the system exposed to $2 \mathrm{ppm} \mathrm{H}_{2} \mathrm{~S}$ is now even further shifted toward the channel outlet as can be seen in Fig. 6c. However, at the fuel outlet, the partial pressures of the gas phase species are still far-off from equilibrium. Thus, the local electromotive force is now reduced over the whole length of the channel causing an even more severe voltage drop.

In order to further understand the spatial evolution of the poisoning behavior, the methane conversion values at the channel inlet, channel outlet and an average over the whole cell were calculated and are depicted in Fig. 7. The methane conversion given in the original paper determined based on the measured OCV, is in good agreement with the averaged methane conversion values shown in Fig. 7. However, in order to allow for a more spatially resolved analysis, it was additionally distinguished between methane conversion at the inlet and outlet. At the channel inlet methane conversion is dramatically reduced and nearly completely blocked already for the lowest $\mathrm{H}_{2} \mathrm{~S}$ concentration of $2 \mathrm{ppm}$. As the $\mathrm{H}_{2} \mathrm{~S}$ concentration is further increased methane conversion at the inlet approaches $0 \%$. However, there is still significant methane conversion at the outlet even for the largest investigated hydrogen sulfide concentrations. In the original paper, a methane conversion of $15 \%$ was calculated for $24 \mathrm{ppm}$ $\mathrm{H}_{2} \mathrm{~S}$ based on OCV measurements. The more detailed calculations depicted in Fig. 7 show that this value refers to the average conversion over the cell whereas the conversion at the outlet is considerably higher. Yet, its value is also decreasing with higher $\mathrm{H}_{2} \mathrm{~S}$ concentrations which would ultimately lead to an almost complete blockage of methane steam reforming reactions.

Previous studies have reported the increased sensitivity of methane reforming towards sulfur poisoning compared to the electrochemical hydrogen oxidation. ${ }^{13,19}$ Based on the given analysis, this is indeed the case as even for a full monolayer of sulfur on Ni the electrochemi- 
cal reactions are still active $e^{5,7,24}$ whereas methane steam reforming is nearly completely blocked.

Cell operation under polarization. - In the second part of this work, we describe SOFC performance degradation due to sulfur formation under current load. All parameters (geometry, (electro-)chemistry) are the same as in the last section. First, three examples at constant current density of $1 \mathrm{~A} \cdot \mathrm{cm}^{-2}$ serve to demonstrate the capabilities of the model. Subsequently, the gas phase species distribution across the cell is shown to allow for a more detailed analysis of the poisoning behavior. Then, the reproduction of impedance spectra before and after $\mathrm{H}_{2} \mathrm{~S}$ addition is shown in order to further establish the model's physically meaningful predictive capabilities.

As described by Rasmussen et al. three voltage stability tests were conducted for gas compositions of $46 \% \mathrm{H}_{2}, 17 \% \mathrm{CH}_{4}, 37 \% \mathrm{H}_{2} \mathrm{O}$ with $\mathrm{H}_{2} \mathrm{~S}$ concentrations of 2 ppm, 4 ppm, 7 ppm and 2 ppm (Test 1), $13 \% \mathrm{H}_{2}, 29 \% \mathrm{CH}_{4}, 58 \% \mathrm{H}_{2} \mathrm{O}$ with an $\mathrm{H}_{2} \mathrm{~S}$ concentration of $2 \mathrm{ppm}$ (Test 2), $13 \% \mathrm{H}_{2}, 29 \% \mathrm{CH}_{4}, 58 \% \mathrm{H}_{2} \mathrm{O}$ with $\mathrm{H}_{2} \mathrm{~S}$ concentrations of 4 ppm, 9 ppm and 7 ppm (Test 3). In test 3 the same fuel gas mixture as in test 2 was employed. However, the initial cell voltage was slightly higher which was accounted for by a higher initial TPB length in our model. A steam to carbon ratio equal or greater than 2 was maintained in all three tests, hence, preventing coke formation. Figure 8 illustrates the comparison between the model predictions and the experimental measurements for these three tests. There are two distinguished regions in the results shown in Fig. 8. First, time periods with cell operation in the absence of $\mathrm{H}_{2} \mathrm{~S}$, where constant slow cell degradation is observed and second, periods exhibiting the characteristic cell voltage reduction after introduction of different $\mathrm{H}_{2} \mathrm{~S}$ concentrations to the anode gas. After switching off the $\mathrm{H}_{2} \mathrm{~S}$ supply the cell voltage regenerates quickly to a level consistent with the overall degradation observed for operation without $\mathrm{H}_{2} \mathrm{~S}$.

Already for cell operation in the absence of sulfur, a slow overall cell degradation can 
be observed which, hence is not sulfur-related. There are many possible reasons for this gradual degradation process, however, in general most of them are associated with decreasing TPB length. Thus, due to limited data available on the actual rate and type of these processes, we modeled the overall cell degradation via a continuous reduction of TPB length. Thus, in the present model we assume that the TPB length of the anode decreases by the following function

$$
l_{\mathrm{N} i / Y S Z}^{\mathrm{V}}=l_{\mathrm{Ni} / \mathrm{YSZ}, 0}^{\mathrm{V}} \cdot e^{-t / \tau},
$$

where $l_{\mathrm{Ni} / \mathrm{YSZ}}^{\mathrm{V}}$ is the TPB length of the $\mathrm{Ni} / \mathrm{YSZ}$ phase, a subscript ${ }_{0}$ denotes the initial TPB length, $t$ is time and $\tau$ is the time constant which is set to $700 \mathrm{~h}$. This can be considered to be a reasonable approach for the present work, since it is not the primary aim of this study to investigate long-term non sulfur related degradation.

In order to study the influence of the initial $\mathrm{CH}_{4}$ concentration, in test 1 the fuel gas contained a significantly higher $\mathrm{H}_{2}$ concentration than in the previous section, and tests 2 and 3. As it can be seen in Fig. 8 the effect of cell poisoning is less severe with larger initial $\mathrm{H}_{2}$

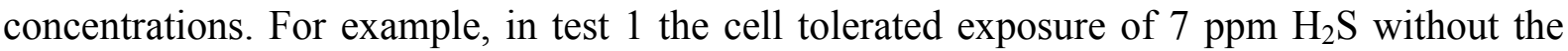
voltage falling below the current turn off voltage of $450 \mathrm{mV}$, whereas in test 3 the same concentration led to an irrecoverable drop below this value. The experimental conditions used to model the experimental results displayed in Fig. 8b correspond to the results shown for OCV stability tests presented in the previous section. At the beginning of the simulation $\left(\right.$ no $\left.\mathrm{H}_{2} \mathrm{~S}\right)$, the cell is operating in steady state, with the inlet fuel rate of $101 \cdot \mathrm{h}^{-1}$ and air flow rate of 140 $1 \cdot h^{-1}$, with an initial cell voltage of $688 \mathrm{mV}$, producing $0.72 \mathrm{~W} \cdot \mathrm{cm}^{-2}$ power density and $57 \%$ fuel utilization. These conditions are maintained for 450 hours until $\mathrm{H}_{2} \mathrm{~S}$ is introduced to the system. After 450 hours, when $\mathrm{H}_{2} \mathrm{~S}$ is introduced to the system, the cell voltage drops from $667 \mathrm{mV}$ to $590 \mathrm{mV}$ over a 24 hour period. Due to the maintenance of the constant current density, the $\mathrm{H}_{2}$ utilization increases within the cell. 
It can be seen that there is a good agreement between simulations and experiments for all three tests. The respective voltage drops could accurately be modeled by sulfur formation on the Ni surface. Thus, it can be concluded that their whole extent over a 24 hour poisoning period is solely due to sulfur chemisorption on $\mathrm{Ni}$ and the associated surface site blockage. Rasmussen et al. have explained the experimentally observed cell voltage breakdown and the associated cell failure in test 1 after the last period of anode exposure to $\mathrm{H}_{2} \mathrm{~S}$ by nickel oxidation due to local fuel starvation at these conditions. Furthermore, the introduction of $9 \mathrm{ppm}$ $\mathrm{H}_{2} \mathrm{~S}$ to the fuel gas in test 3 led to an almost immediate cell voltage drop below $450 \mathrm{mV}$ resulting in an automatic current turn off. Subsequently, after the same current load was applied

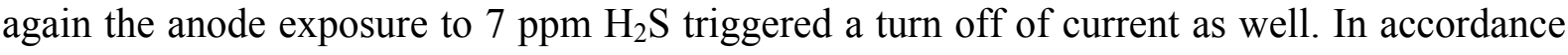
with the experiments in our simulations for $9 \mathrm{ppm}_{2} \mathrm{~S}$ a cell voltage drop below $450 \mathrm{mV}$ was calculated. However, the subsequent performance drop for $7 \mathrm{ppm} \mathrm{H}_{2} \mathrm{~S}$ clearly results in a final voltage greater than $450 \mathrm{mV}$. The authors of the original paper have explained the experimental behavior by the high fuel utilization of $>90 \%$ leading to Ni oxidation. We have not attempted to account for these Ni oxidation processes in the present model, thus, it comes to a deviation between experiment and simulation in the mentioned cases. Rasmussen et al. have observed the recovery of the cells in the methane-containing fuel to be faster than the recovery in $\mathrm{H}_{2} / \mathrm{H}_{2} \mathrm{O}$ fuel indicating a faster sulfur removal from the surface. This characteristic behavior was also successfully reproduced with the employed model. Taking into account the observation of the domino effect-like behavior illustrated in Fig. 6, the rapid recovery in methane-containing fuel is suggested to be due to an increase of hydrogen partial pressure as the surface area becomes gradually available again for methane reforming.

A further analysis of the results presented in Fig. $8 \mathrm{~b}$ is shown in Fig. 9. Similarly to the results shown in Fig. 6, the gas species distribution is plotted for the channel (horizontal panel) and the anode (drop down vertical panel for three positions within the channel). Fig. 9a shows results for the system without the presence of $\mathrm{H}_{2} \mathrm{~S}$ in the gas phase, and Fig. $9 \mathrm{~b}$ illus- 
trates the sulfur poisoning effect for an $\mathrm{H}_{2} \mathrm{~S}$ gas phase concentration of $2 \mathrm{ppm}$. Fig. 9a shows that as methane enters the channel, it is rapidly reformed to $\mathrm{H}_{2}$ and $\mathrm{CO}$. Two local maxima can be observed in the $\mathrm{H}_{2}$ and $\mathrm{CO}$ mole fractions at approximately $0.5 \mathrm{~cm}$ after the channel inlet. These maxima can be attributed to the fact that reforming chemistry consumes $\mathrm{CH}_{4}$ faster than $\mathrm{H}_{2}$ is oxidized electrochemically. As soon as methane is completely converted, the partial pressure of hydrogen starts to decrease due to its electrochemical oxidation. The accompanying accumulation of steam in the anode also leads to a promotion of the WGS reaction. Thus, the evolution of the concentrations of $\mathrm{CO}$ and $\mathrm{H}_{2}$ display the same trends. It shall be pointed out at this point that even though it is possible to achieve stable SOFC performance with $\mathrm{CO} / \mathrm{CO}_{2}$ mixtures, ${ }^{46,47}$ it was shown that in reformate-fueled ASCs only hydrogen is oxidized due to the rapid kinetics of the water gas shift reaction on $\mathrm{Ni}^{48}$ Hence, the evolution of the gas phase concentrations of $\mathrm{CO}$ and $\mathrm{CO}_{2}$ is only related to the reforming reactions.

Along the whole length of the channel, as a result of the generally increased water content and thus, shifted WGS equilibrium, the mole fraction of $\mathrm{CO}_{2}$ is higher and the mole fraction of $\mathrm{CO}$ is lower than at $\mathrm{OCV}$.

Analogous to Fig. 6b, exposure of the anode to $\mathrm{H}_{2} \mathrm{~S}$ shifts the main reaction zone of methane reforming towards the middle of the channel. As hydrogen is still electrochemically oxidized at the channel inlet, its mole fraction reaches a minimum at around one third of the channel length. The existence of this minimum clearly demonstrates the increased sensitivity of methane steam reforming towards sulfur poisoning in comparison to the electrochemical hydrogen oxidation reactions. It can be concluded that a further increase in $\mathrm{H}_{2} \mathrm{~S}$ concentration would eventually lead to a nearly complete lack of hydrogen in some parts of the anode and thus, a corresponding oxidation of the Ni particles.

Once the reforming reactions are initiated, the hydrogen mole fraction increases and reaches a maximum at full methane conversion. As a consequence of the large water content in the system and the resulting promotion of the WGS reaction, the $\mathrm{CO}_{2}$ mole fraction at the 
channel end is greater under polarization than at OCV conditions.

At this point it should be noted that the formation of $\mathrm{NiO}$ is certainly possible for the conditions observed in Fig. 8c. As it is mentioned above, the exposure of the system to $7 \mathrm{ppm}$ $\mathrm{H}_{2} \mathrm{~S}$ (Test 3) leads to the failure of the cell, presumably due to Ni oxidation. Indeed at the time point of about $1150 \mathrm{~h}$, where a significant voltage drop is observed, the local $p \mathrm{H}_{2} / p \mathrm{H}_{2} \mathrm{O}$ ratio is very small $(0.005)$ and fuel utilization reaches $\sim 95 \%$. This is a strong indication that $\mathrm{Ni}$ could be oxidized in these conditions leading to a breakdown of the cell. However, the inclusion of such complex $\mathrm{NiO}$ formation process and its effect on the enthalpy of sulfur is currently not possible due to limited information in the prior literature. Thus, in order to focus on the primary aim of the present work this phenomenon was not considered in the model.

In order to demonstrate the physical accuracy of our model and its parameters, impedance spectra were reproduced before and after exposure of the Ni/YSZ anode to $\mathrm{H}_{2} \mathrm{~S}$. The corresponding Nyquist plot in Fig. 10a shows the comparison between the experimental and simulated impedance responses. The experimental impedance spectra for the poisoned cell were measured for test 2 as shown in Fig. 8 with an $\mathrm{H}_{2} \mathrm{~S}$ concentration of 2 ppm after the cell voltage stabilization. Simulations and experiments show a very good agreement both before and after the cell poisoning. Under $\mathrm{H}_{2} \mathrm{~S}$ exposure a significant increase of total cell resistance is observed in correlation with an enlargement of the middle-frequency arc. The sulfur poisoning effect is further demonstrated by the corresponding Bode plots in Fig. 10b that, under sulfur exposure, exhibit an increase of the imaginary part of the impedance mainly in the frequency range between $10^{1}$ and $10^{2} \mathrm{~Hz}$. This effect has already been observed in previous studies and was related to hindered charge transfer and surface chemistry processes. ${ }^{13,18,24}$

In order to shed light on the mechanistic understanding of the surface processes leading to sulfur poisoning of SOFC operated with methane, the sulfur surface coverage on Ni depending on the cell current density is shown in Fig. 11. It should be noted that the depicted surface coverage values were obtained after the completion of the cell voltage drop as depict- 
ed in Fig. $8 \mathrm{~b}$ for steady-state conditions. No overall cell degradation was assumed to occur during the respective calculations, i.e. the TPB length was held constant. It can be seen that sulfur surface coverage is increasing with current density. At high current densities, sulfur coverage is already close to saturation $(0.5 \mathrm{ML})$ for $2 \mathrm{ppm}$ demonstrating the high sensitivity of methane-fueled Ni/YSZ anodes towards sulfur poisoning. In our recent kinetic study we have already observed a similar behavior in $\mathrm{H}_{2} / \mathrm{H}_{2} \mathrm{O}$ fuels as well, where we have related the increase in sulfur coverage to the enhanced electrochemical hydrogen oxidation at high current densities and the associated hydrogen removal from the surface. ${ }^{24}$ In contrast to multiple experimental sources suggesting a decrease of sulfur coverage with current density we have shown the opposite behavior while successfully reproducing experimental data over a wide range of operating conditions. This behavior was already recently questioned in both experimental and theoretical studies. ${ }^{18,26,49}$ For example, Cheng et al. have indicated that a decreasing relative total anode resistance with current density is the inherent behavior of the Tafel region. $^{26}$

In both our recent and our present study good agreement between experiments and simulation was achieved without the inclusion of an electrochemical sulfur oxidation reaction, the macroscopic impact of such a hypothetical process can be put into question. As shown in Fig. $9 \mathrm{~b}$ the increasing rate of hydrogen oxidation decreases the hydrogen partial pressure in the gas phase which lowers the driving force of sulfur removal as equilibrium in Eq. 3 is shifted to the left.

$$
\mathrm{S}_{\mathrm{Ni}}+\mathrm{H}_{2, \mathrm{~g}} \rightleftharpoons \mathrm{H}_{2} \mathrm{~S}+\square_{\mathrm{Ni}}
$$

In this regard, the reduced partial pressure of hydrogen in the gas phase has two convoluted effects: first, the increase of sulfur coverage as a result of a shifted equilibrium in the above reaction and second, the decrease of the local electromotive force between anode and cathode which appears due to the altered gas phase composition in the anode. 


\section{Summary and Conclusions}

We have presented an elementary kinetic model to represent degradation caused by sulfur poisoning in the porous Ni/YSZ anode of anode-supported SOFC operated on methanecontaining fuels. Our previously developed detailed multi-step reaction mechanism of sulfur formation and oxidation was coupled with complex heterogeneous methane reforming chemistry, channel gas-flow, porous-media transport and elementary charge-transfer chemistry, to illustrate important aspects of SOFC cell performance degradation. Throughout the work, an elementary kinetic approach was used which allows for a mechanistic interpretation of the experimentally observed poisoning behavior.

Using literature experimental data including characteristic voltage drops under transient conditions and impedance spectra, sulfur-induced degradation was described under different operating conditions. Comparisons of model predictions with experiments showed that the developed model, without any modifications, enables an accurate representation of the poisoning processes capturing their effect on methane conversion and selectivity.

It was shown that atomically adsorbed sulfur significantly affects heterogeneous reforming chemistry, suppressing hydrogen and carbon monoxide production and causing a significant degradation of the cell voltage already at the open circuit voltage. The blockage of the reforming reaction is particularly pronounced at the fuel gas inlet and advances along the channel with increasing hydrogen sulfide concentration and current density. At constant current densities, the poisoning behavior of $\mathrm{Ni} / \mathrm{YSZ}$ anode operated on methane-containing fuels is illustrated by a non-linear cell voltage decrease. Spatially resolved analyses of the gas phase distributions have shown the hazard of local fuel starvation already at low $\mathrm{H}_{2} \mathrm{~S}$ concentrations potentially causing cell failure. Under polarization, the high susceptibility of Ni/YSZ anodes to sulfur poisoning in methane-containing fuels was explained by a restricted supply of fuel gases. Furthermore, sulfur coverage on Ni was shown to increase with current density. 
The developed model will form the basis for future investigations on the interplay between sulfur poisoning and carbon formation at the Ni/YSZ anode and on the sulfur poisoning of the water gas shift reaction.

\section{Acknowledgments}

We gratefully acknowledge financial support by the German Ministry of Education and Research (BMBF) via grant number 03SF0494C and by the European Union's Seventh Framework Programme (FP7/2007-2013) for the Fuel Cells and Hydrogen Joint Technology Initiative under grant agreement $n^{\circ} 303429$. We are especially grateful to Prof. Anke Hagen (Technical University of Denmark) for insightful discussions and for generous sharing of her experimental data. 


\section{References}

1. Y. Shiratori, T. Ijichi, T. Oshima, and K. Sasaki, Int. J. Hydrogen Energy, 35, 7905 (2010).

2. P. Kowalik, K. Antoniak-Jurak, M. Błesznowski, M. C. Herrera, M. A. Larrubia, L. J. Alemany, and I. S. Pieta, Catal. Today, 254, 129 (2015).

3. M. Andersson, H. Paradis, J. Yuan, and B. Sundén, J. Fuel Cell Sci. Technol., 8, 031013 (2011).

4. K. Sasaki, K. Susuki, A. Iyoshi, M. Uchimura, N. Imamura, H. Kusaba, Y. Teraoka, H. Fuchino, K. Tsujimoto, Y. Uchida, and N. Jingo, J. Electrochem. Soc., 153, A2023 (2006).

5. S. Zha, Z. Cheng, and M. Liu, J. Electrochem. Soc., 154, B201 (2007).

6. Z. Cheng, S. Zha, and M. Liu, J. Power Sources, 172, 688 (2007).

7. Y. Matsuzaki and I. Yasuda, Solid State Ionics, 132, 261 (2000).

8. A. Lussier, S. Sofie, J. Dvorak, and Y. Idzerda, Int. J. Hydrogen Energy, 33, 3945 (2008).

9. L. Yang, Z. Cheng, M. Liu, and L. Wilson, Energy Environ. Sci., 3, 1804 (2010).

10. J. F. B. Rasmussen and A. Hagen, J. Power Sources, 191, 534 (2009).

11. T. R. Smith, A. Wood, and V. I. Birss, Appl. Catal. A Gen., 354, 1 (2009).

12. T. Yoshizumi, C. Uryu, T. Oshima, and Y. Shiratori, ECS Trans., 35, 1717 (2011).

13. J. F. B. Rasmussen and A. Hagen, Fuel Cells, 10, 1135 (2010).

14. A. Weber, S. Dierickx, A. Kromp, and E. Ivers-Tiffée, Fuel Cells, 13, 487 (2013). 
15. T. S. Li, M. Xu, C. Gao, B. Wang, X. Liu, B. Li, and W. G. Wang, J. Power Sources, 258, 1 (2014).

16. A. Hagen, J. Electrochem. Soc., 160, F111 (2013).

17. A. Hauch, A. Hagen, J. Hjelm, and T. Ramos, J. Electrochem. Soc., 161, F734 (2014).

18. A. Hagen, G. B. Johnson, and P. Hjalmarsson, J. Power Sources, 272, 776 (2014).

19. A. Hagen, J. F. B. Rasmussen, and K. Thydén, J. Power Sources, 196, 7271 (2011).

20. J. R. Rostrup-Nielsen, J. B. Hansen, S. Helveg, N. Christiansen, and A. K. Jannasch, Appl. Phys. A, 85, 427 (2006).

21. M. Noponen, M. Halinen, J. Kiviaho, and J. Saarinen, J. Fuel Cell Sci. Technol., 3, 438 (2006).

22. H. P. He, A. Wood, D. Steedman, and M. Tilleman, Solid State Ionics, 179, 1478 (2008).

23. A. Kromp, S. Dierickx, A. Leonide, A. Weber, and E. Ivers-Tiffée, J. Electrochem. Soc., 159, B597 (2012).

24. M. Riegraf, G. Schiller, R. Costa, K. Andreas Friedrich, A. Latz, and V. Yurkiv, J. Electrochem. Soc., 162, F65 (2015).

25. E. Brightman, D. G. Ivey, D. J. L. Brett, and N. P. Brandon, J. Power Sources, 196, 7182 (2011).

26. Z. Cheng, J.-H. Wang, Y. Choi, L. Yang, M. C. Lin, and M. Liu, Energy Environ. Sci., 4, $4380(2011)$.

27. W. G. Bessler, S. Gewies, and M. Vogler, Electrochim. Acta, 53, 1782 (2007). 
28. B. Horstmann, T. Danner, and W. G. Bessler, Energy Environ. Sci., 6, 1299 (2013).

29. T. Danner, B. Horstmann, D. Wittmaier, N. Wagner, and W. G. Bessler, J. Power Sources, 264, 320 (2014).

30. G. K. Gupta, E. S. Hecht, H. Zhu, A. M. Dean, and R. J. Kee, J. Power Sources, 156, 434 (2006).

31. A. Bertei, J. Mertens, and C. Nicolella, Electrochim. Acta, 146, 151 (2014).

32. N. M. Galea, J. M. H. Lo, and T. Ziegler, J. Catal., 263, 380 (2009).

33. C. H. Bartholomew, P. K. Agrawal, and J. R. Katzer, Adv. Catal., 31, 135 (1982).

34. M. Perdereau and J. Oudar, Surf. Sci., 20, 80 (1970).

35. V. Yurkiv, R. Costa, Z. Ilhan, A. Ansar, and W. G. Bessler, J. Electrochem. Soc., 161, F480 (2014).

36. P. Deuflhard, E. Hairer, and J. Zugck, Numer. Math., 51, 501 (1987).

37. W. G. Bessler, Solid State Ionics, 176, 997 (2005).

38. L. Maier, B. Schädel, K. Herrera Delgado, S. Tischer, and O. Deutschmann, Top. Catal., 54, $845(2011)$.

39. V. Yurkiv, Electrochim. Acta, 143, 114 (2014).

40. H. Zhu, R. J. Kee, V. M. Janardhanan, O. Deutschmann, and D. G. Goodwin, J. Electrochem. Soc., 152, A2427 (2005). 
41. E. S. Hecht, G. K. Gupta, H. Zhu, A. M. Dean, R. J. Kee, L. Maier, and O. Deutschmann, Appl. Catal. A Gen., 295, 40 (2005).

42. R. J. Kee, H. Zhu, and D. G. Goodwin, Proc. Comb. Inst., 30, 2379 (2005).

43. M. Vogler, A. Bieberle-Hütter, L. Gauckler, J. Warnatz, and W. G. Bessler, J. Electrochem. Soc., 156, B663 (2009).

44. J. Oudar, Catal. Rev. Eng., 22, 171 (1980).

45. I. Alstrup, J. Rostrup-Nielsen, and S. Røen, Appl. Catal., 1, 303 (1981).

46. V. Yurkiv, A. Utz, A. Weber, E. Ivers-Tiffée, H.-R. Volpp, and W. G. Bessler, Electrochim. Acta, 59, 573 (2012).

47. A. Utz, A. Leonide, A. Weber, and E. Ivers-Tiffée, J. Power Sources, 196, 7217 (2011).

48. A. Kromp, A. Leonide, A. Weber, and E. Ivers-Tiffée, J. Electrochem. Soc., 158, B980 (2011).

49. V. M. Janardhanan and D. S. Monder, J. Electrochem. Soc., 161, F1427 (2014).

50. D. G. Goodwin, H. Zhu, A. M. Colclasure, and R. J. Kee, J. Electrochem. Soc., 156, B1004 (2009). 


\section{List of Tables}

Table I. Model parameters used for the simulations. 
Anode Ni/YSZ

Thickness, $d_{\mathrm{Ni} / \mathrm{YSZ}}$

Anode/gas surface specific area

Anode TPB length

Anode porosity, $\varepsilon$

Anode tortuosity, $\tau$

Ni particle radius

Pore size, $d_{\mathrm{P}, \mathrm{A}}$

Interfacial DL capacitance, $C_{\mathrm{DL}}^{\mathrm{In}}$
$315 \mu \mathrm{m}$

13

$3.0 \cdot 10^{12} \mathrm{~m} \cdot \mathrm{m}^{-2} \quad$ Estimated

0.3

Estimated

Assumed

Assumed

Assumed

Fit

Thickness, $d_{\mathrm{LSM} / \mathrm{YSZ}}$

Cathode TPB length

Cathode porosity, $\varepsilon$

Cathode tortuosity, $\tau$

LSM particle radius

Pore size, $d_{\mathrm{P}, \mathrm{C}}$

Interfacial DL capacitance, $C_{\mathrm{DL}}^{\mathrm{In}}$
$25 \mu \mathrm{m}$

$5.0 \cdot 10^{-5} \mathrm{~m}$

0.3

2

$1 \mu \mathrm{m}$

$1 \mu \mathrm{m}$

$2 \mathrm{~F} \cdot \mathrm{m}^{-2}$

$15 \mu \mathrm{m}$

$T /\left(1.4 \cdot 10^{7} \mathrm{~K}\right) \cdot \mathrm{e}^{\left(90000 \mathrm{~J} / k_{\mathrm{B}} T\right)}$
13

Estimated

Estimated

Estimated

Estimated

Estimated

Fit

Thickness, $d_{\mathrm{YSZ}}$

Ionic conductivity of bulk YSZ,

Electrolyte, YSZ 
$\sigma_{\mathrm{YSZ}}$

Surface site density, $\Gamma_{\text {YSZ }}$

Bulk density, $\rho_{\mathrm{YSZ}}$

Bulk vacancy/oxygen fraction
$\mathrm{S} / \mathrm{m}$

$1.1 \cdot 10^{-5} \mathrm{~mol} \cdot \mathrm{m}^{-2} \quad 46,50$

$6800 \mathrm{~kg} \cdot \mathrm{m}^{-3}$

46,50

$\begin{array}{ll}0.0401 / 0.9599 & 46,50\end{array}$

Gas channel

Length, $D_{\text {ch }} \quad 0.04 \mathrm{~m}$

Thickness, $d_{\mathrm{ch}} \quad 1.0 \cdot 10^{-4} \mathrm{~m}$

Inflow velocity $\quad 10 \mathrm{l} \cdot \mathrm{h}^{-1}($ fuel $), 140 \mathrm{l} \cdot \mathrm{h}^{-1} \quad 13$

(air)

Experimental conditions

Temperature, $T$

$1123 \mathrm{~K}$

13

Pressure, $p \quad 1$ atm 13

Anode gas composition

$13 \% \mathrm{H}_{2}, 29 \% \mathrm{CH}_{4}$,

13

$58 \% \mathrm{H}_{2} \mathrm{O}^{\mathrm{a}}$

Cathode gas composition

$21 \% \mathrm{O}_{2}, 79 \% \mathrm{~N}_{2}$

13

${ }^{\mathrm{a}}$ When another gas phase composition is used, it is described in the respective section 
Figure Captions

Figure 1. Schematic illustration of a Ni/YSZ anode-supported planar SOFC including the general representation of some physico-chemical processes. All structural details and scaling are exaggerated merely for illustration purposes.

Figure 2. Schematic illustration of the combined methane reforming and sulfur formation/oxidation reaction mechanism.

Figure 3. Predicted cell voltage (full, black line) and power density (dashed, blue line) as functions of current density at $1123 \mathrm{~K}$ for a gas mixture of $13 \% \mathrm{H}_{2}, 29 \% \mathrm{CH}_{4}, 58 \% \mathrm{H}_{2} \mathrm{O}$. The additional axis on the right shows fuel and air utilization (in percentage) as function of current density (green, dashed-dotted line).

Figure 4. Comparison of the cell voltage (OCV) development at different $\mathrm{H}_{2} \mathrm{~S}$ concentrations between simulation (solid line) and experiments (open symbols) at $T=1123 \mathrm{~K}$ for $13 \% \mathrm{H}_{2}$, $29 \% \mathrm{CH}_{4}, 58 \% \mathrm{H}_{2} \mathrm{O}$.

Figure 5. The coverages of selected species on the Ni surface during cell poisoning with 2, 4, 7, 9, 20 and 24 ppm of $\mathrm{H}_{2} \mathrm{~S}$. Experimental conditions are the same as for the results in Fig. 4.

Figure 6. Spatial distribution of gas phase species along the anode channel (horizontal panel) and inside the porous anode at three different positions in the channel (vertical panel), and at the time of 6 hours $\left(\mathrm{a}-\right.$ no $\left.\mathrm{H}_{2} \mathrm{~S}\right), 50$ hours $(\mathrm{b}-2 \mathrm{ppm})$ and 220 hours $(\mathrm{c}-24 \mathrm{ppm})$.

Figure 7. Methane conversion as the function of $\mathrm{H}_{2} \mathrm{~S}$ concentration: green curve - at the cell 
inlet, blue curve - at the cell outlet and black curve - average through the cell.

Figure 8. Comparison of the cell voltage development at different $\mathrm{H}_{2} \mathrm{~S}$ concentrations and inlet gas mixture (test 1, 2, 3) between model (solid line) and experimental measurements (open symbols) at $T=1123 \mathrm{~K}$.

Figure 9. Spatial distribution of gas phase species along the channel (horizontal panel) and inside the porous anode for three different positions along the channel (vertical panel), at the time of 150 hours $\left(\mathrm{a}-\right.$ no $\left.\mathrm{H}_{2} \mathrm{~S}\right), 460$ hours $(\mathrm{b}-2 \mathrm{ppm})$. The corresponding voltage stability test is shown in Fig. 8b.

Figure 10. (a) Nyquist and (b) Bode plots of impedance spectra at a temperature of $1123 \mathrm{~K}$ and pressure of $1 \mathrm{~atm}$ before and after cell exposure to $2 \mathrm{ppm} \mathrm{H}_{2} \mathrm{~S}$ at $1 \mathrm{~A} \cdot \mathrm{cm}^{-2}$. Nyquist plots are depicted for experiments (open symbols) and simulations (solid lines). As there is no experimental data given for the Bode plots, only simulation results are shown. The black lines in the plots represent the non-sulfur system, the blue lines exhibit the impedance after $\mathrm{H}_{2} \mathrm{~S}$ exposure.

Figure 11. The change of sulfur coverage with cell current density for an $\mathrm{H}_{2} \mathrm{~S}$ gas phase concentration of $2 \mathrm{ppm}$. 

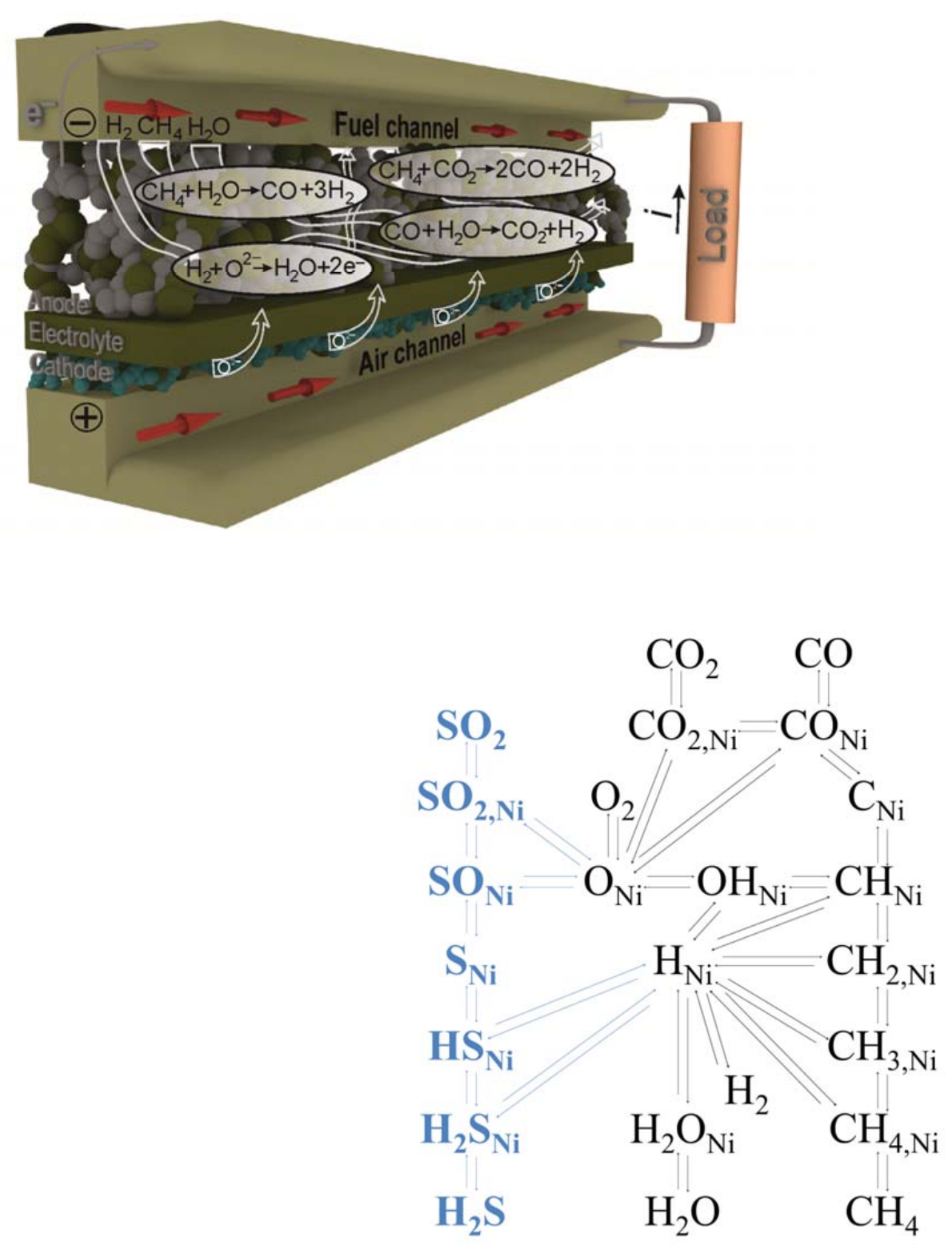

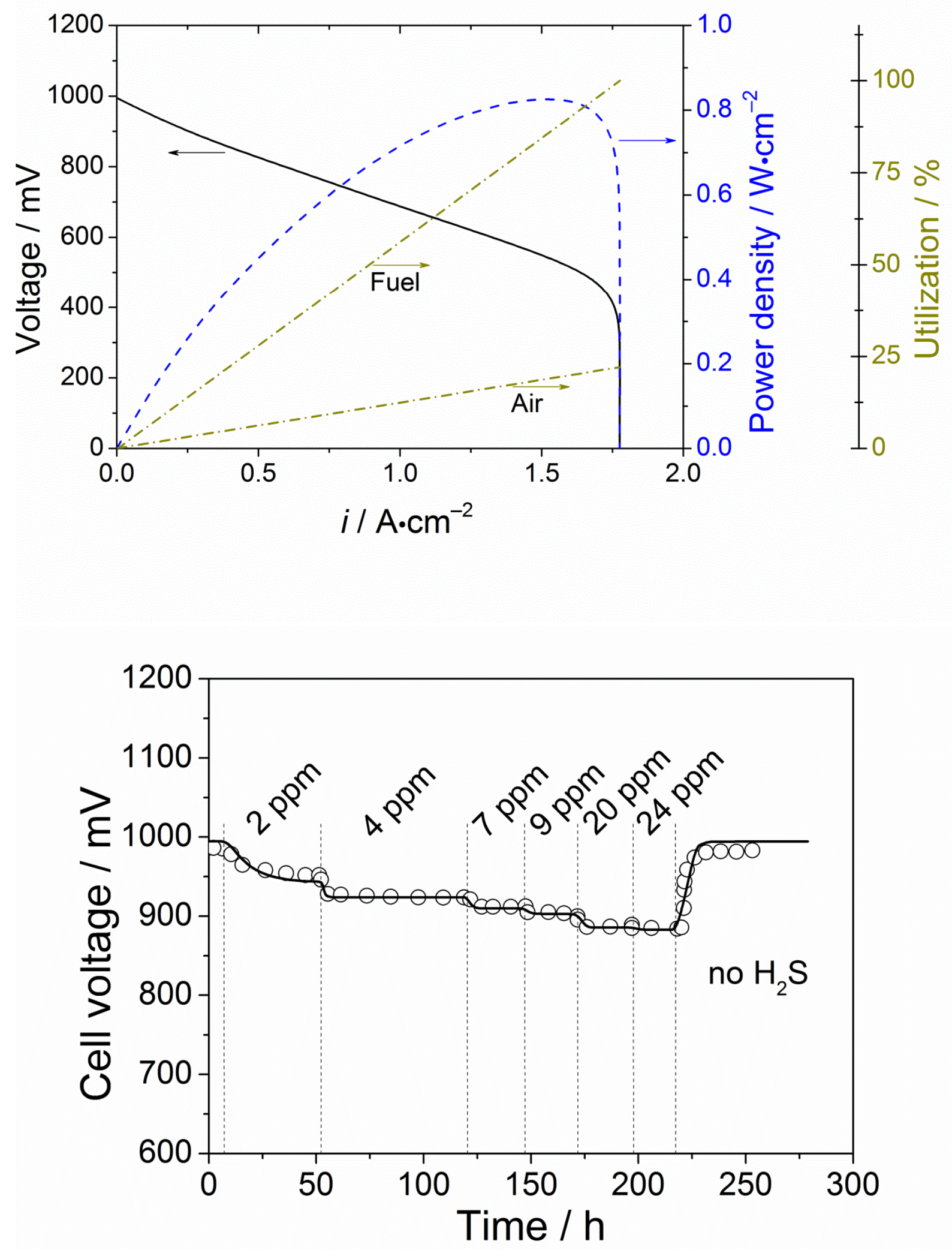

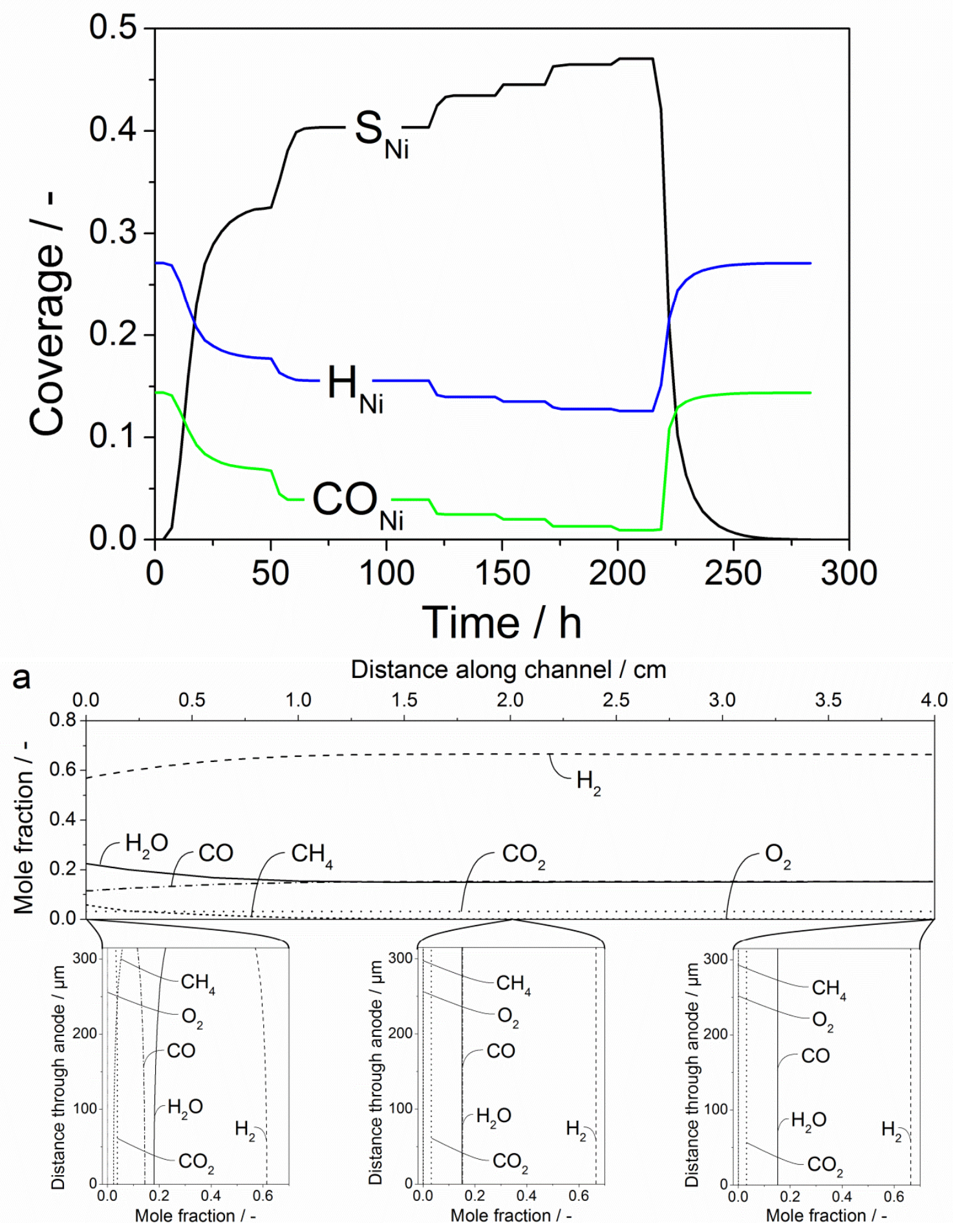


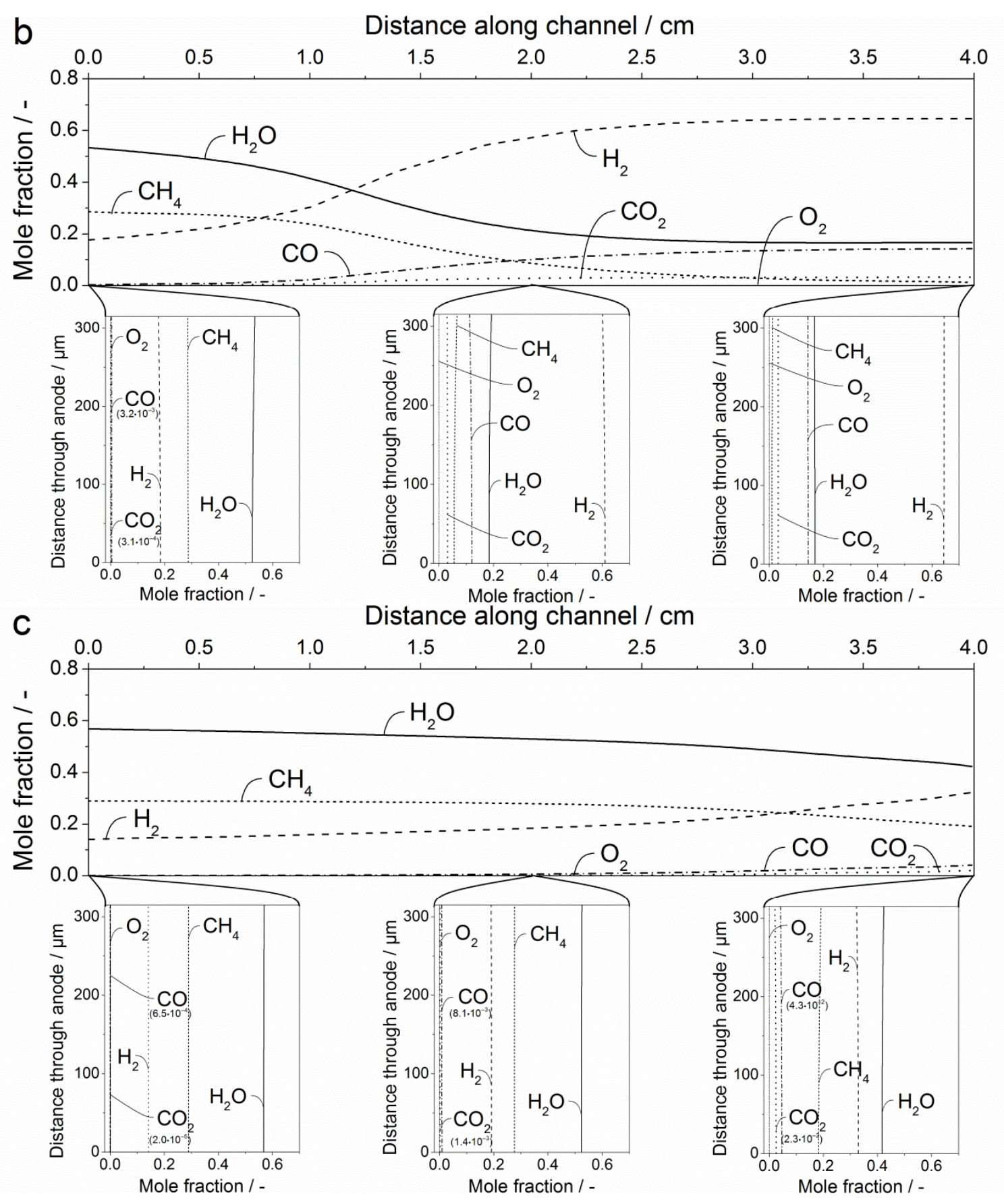



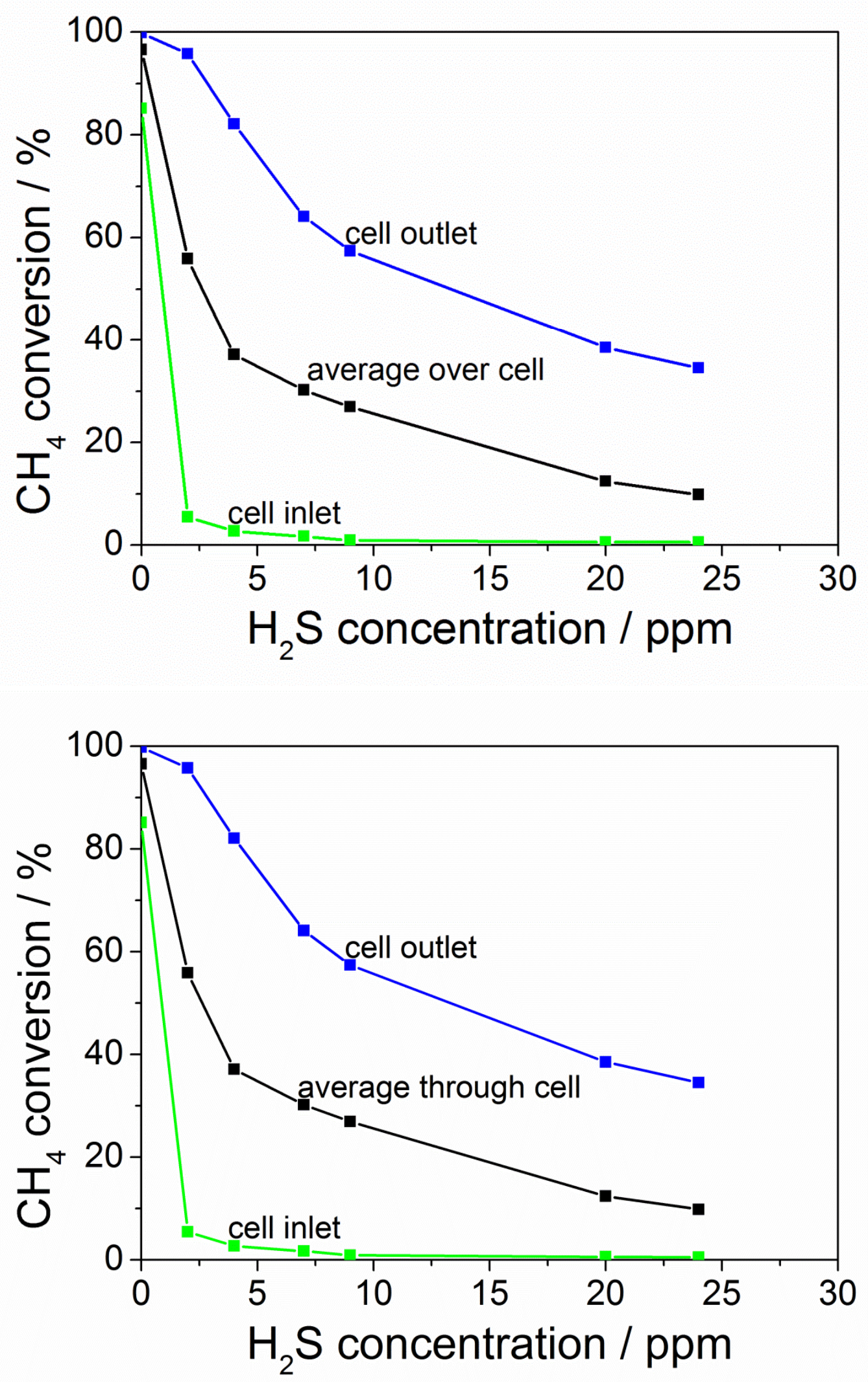


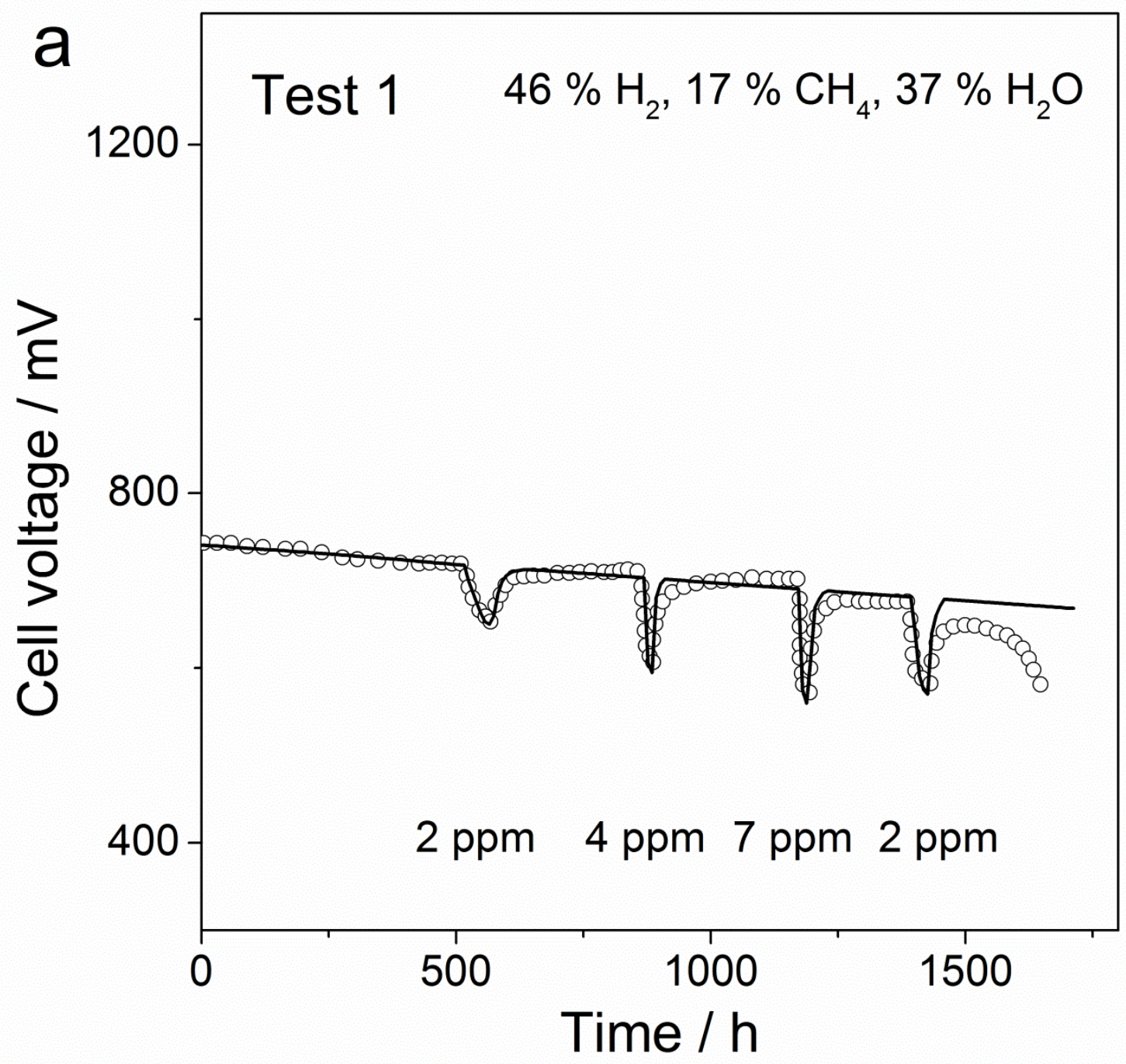




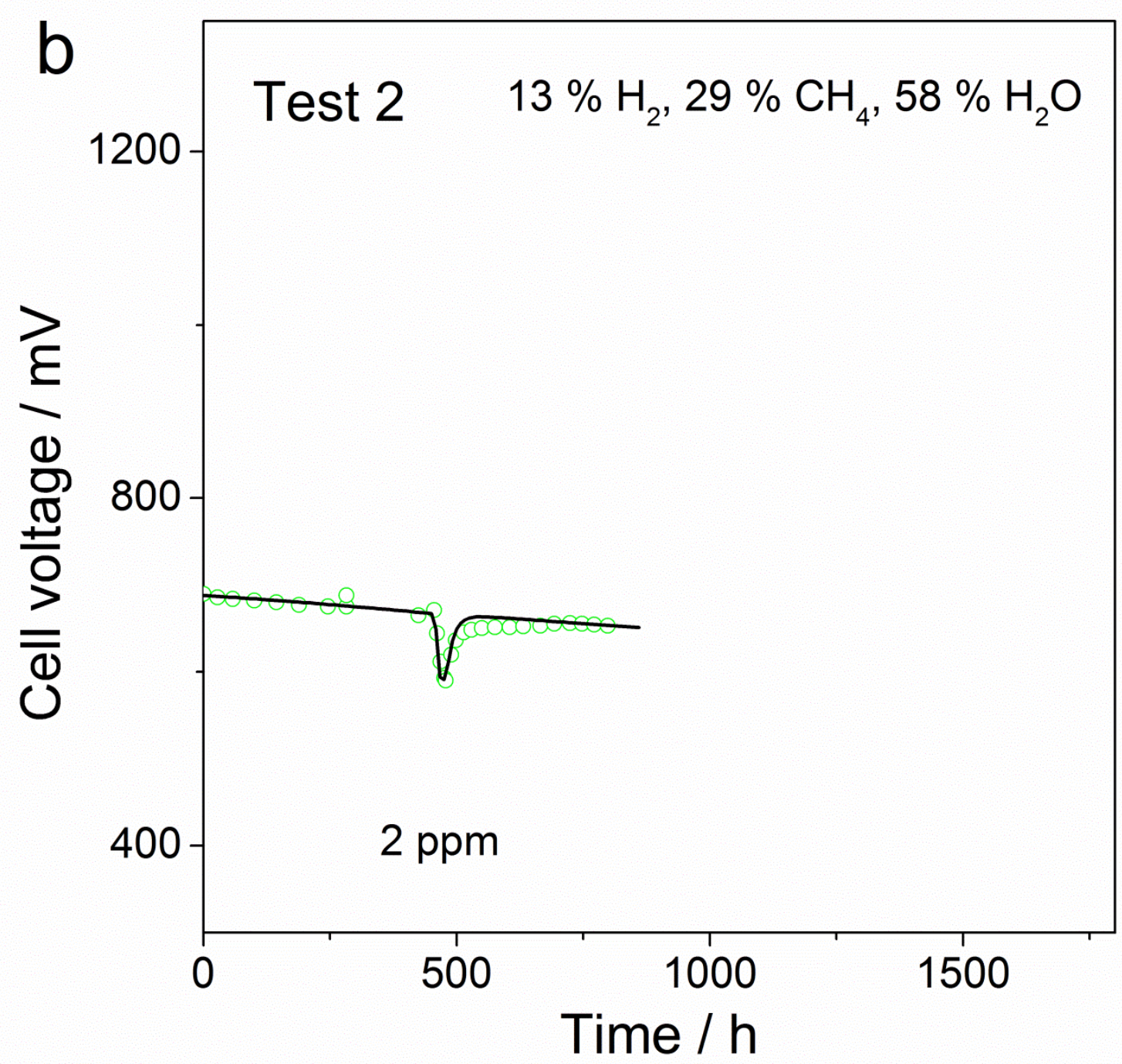



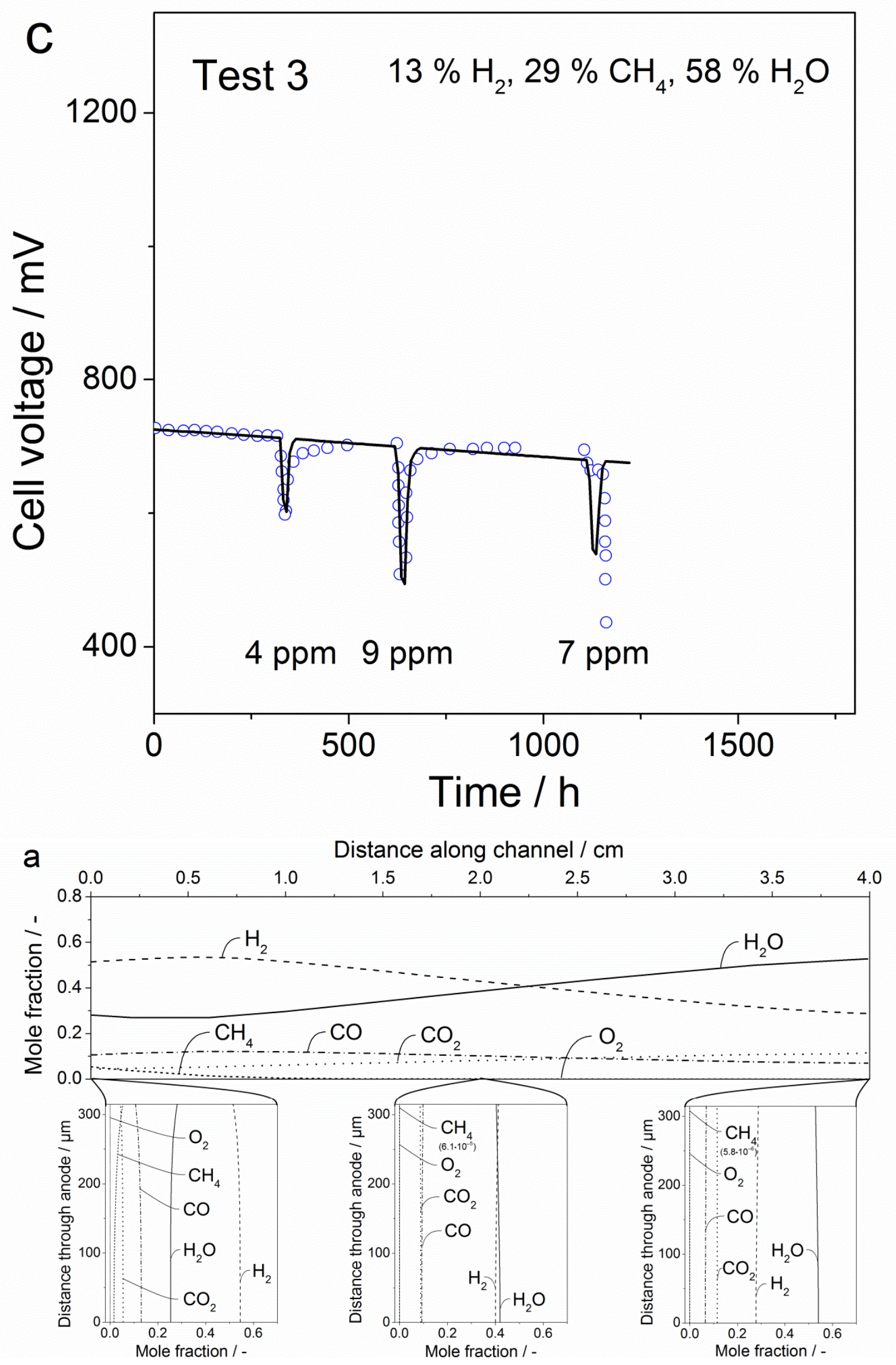

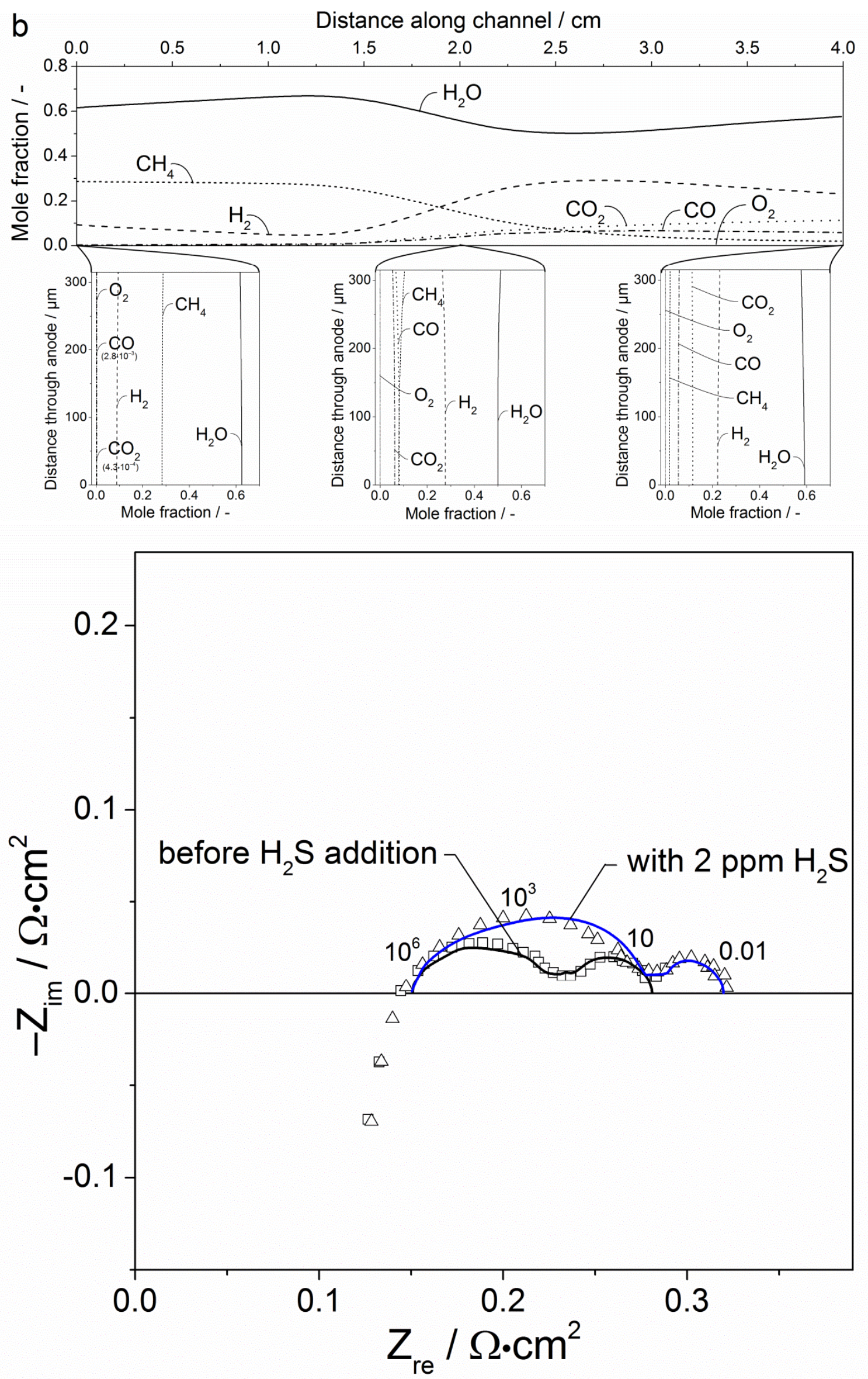


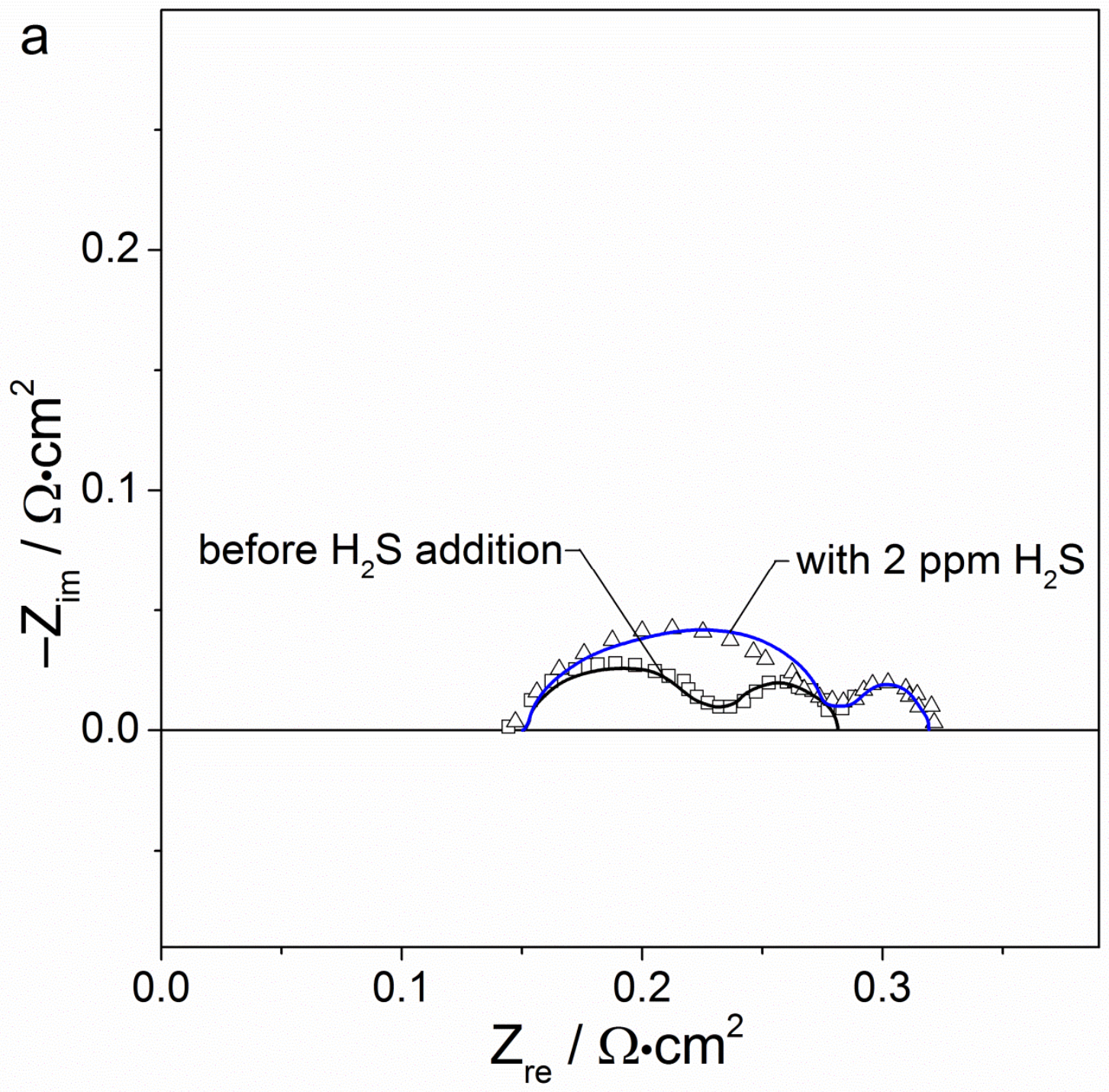



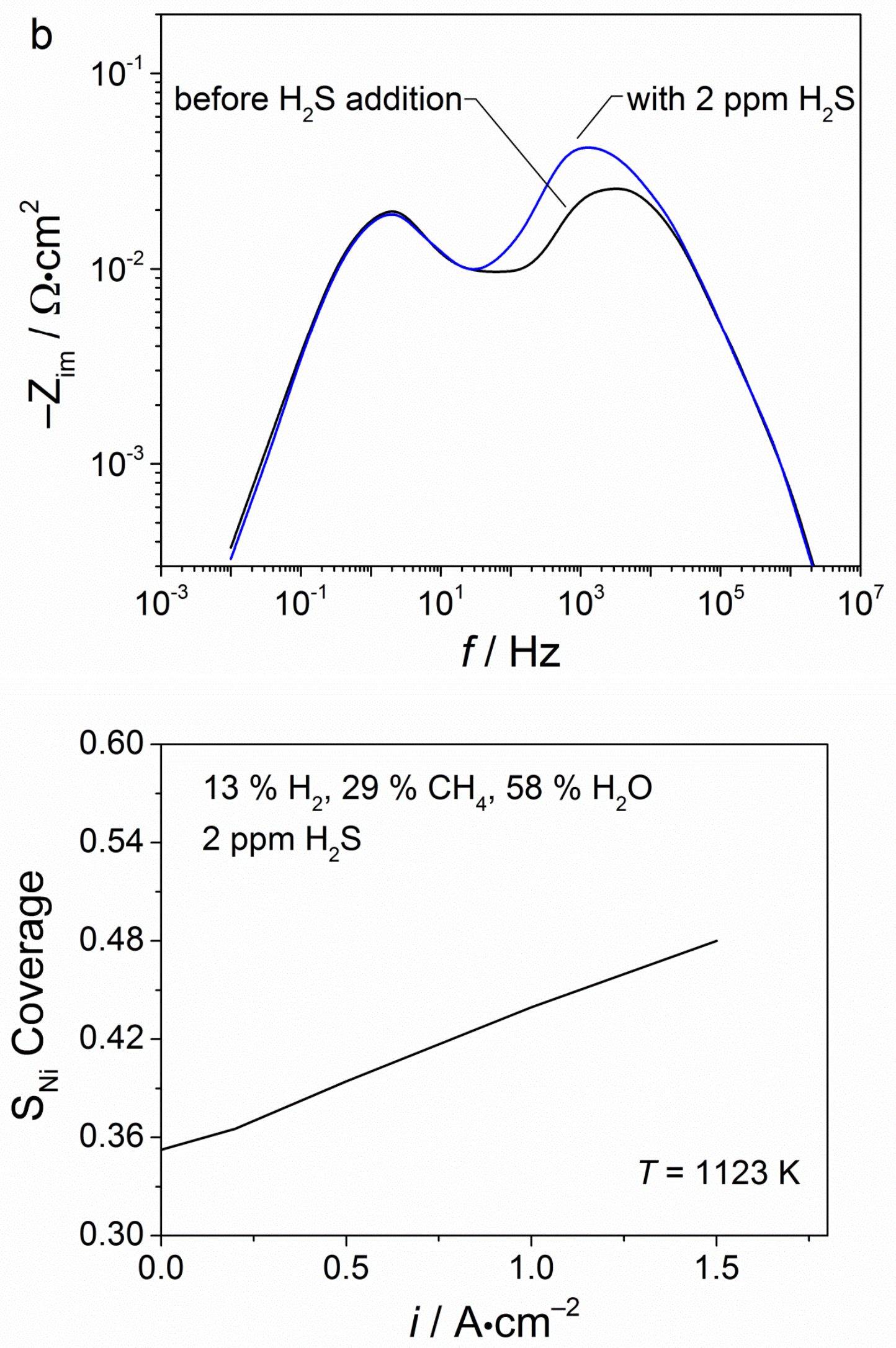